\title{
AS OCUPAÇÕES DO MOVIMENTO OLGA BENÁRIO E A DESOBEDIÊNCIA CIVIL FEMINISTA
}

\author{
Amanda Carolina Cegatti ${ }^{1}$
}

RESUMO: Desde 2016, militantes do Movimento Olga Benário ocuparam três residências inabitadas em diferentes cidades e as transformaram em Casas de Referência para Mulheres em situação de violência. A primeira delas, a Casa Tina Martins (Belo Horizonte/MG), se inicia com o intuito de pressionar os governantes a tomar parte na responsabilidade de proteção às mulheres e, posteriormente, soma-se à rede de enfrentamento à violência já existente. Inspiradas nesta ação, as outras duas ocupações, Mulheres Mirabal (Porto Alegre/RS) e Helenira Preta (Mauá/SP), surgem com a finalidade de oferecer um espaço de abrigamento às mulheres, além de buscar pressionar o Estado. Considerando que estes parecem ser os objetivos principais do movimento, e não o de contestar a legalidade da propriedade a partir da ocupação dos imóveis, pretende-se identificar se as militantes consideram suas ações como desobediência civil e com o a justificam. Com o aporte dos estudos sobre movimentos feministas e desobediência civil, busca-se compreender as motivações subjacentes à atuação do Movimento e das respectivas ocupações, bem como seus objetivos mais abrangentes; paralelamente, procura-se identificar a interlocução do Movimento com as diferentes vertentes feministas. As informações foram obtidas em entrevistas com as lideranças do Olga Benário e das ocupações, e no site do Movimento e das Casas, o que permitiu identificar o fim último da organização, bem como os valores feministas que orientam as suas ações.

Palavras-chave: Movimento Olga Benário. Desobediência Civil. Feminismos

\section{INTRODUÇÃO}

Em 8 de março de 2016, Dia Internacional da Mulher, militantes do Movimento Olga Benário ocuparam o bandejão da Universidade Federal de Minas Gerais (UFMG), com o intuito de dar visibilidade às suas demandas por responsabilização do Estado perante às situações de violência contra a mulher. A ocupação, que duraria um dia, manteve-se por 89 dias, pois se tornou um local de acolhimento espontâneo procurado por mulheres da cidade que descobriram o teor do ação. Após barganharem com o estado mineiro, as militantes instalaram-se em um imóvel concedido pelo governo e oficializaram o que, atualmente, é conhecida como Casa de Referência da Mulher Tina Martins (SUAREZ, 2016).

\footnotetext{
1 Doutoranda e Mestra pelo Programa de Pós-Graduação em Ciência Política da Universidade Federal do Rio Grande do Sul (UFRGS). Bacharela em Relações Internacionais pela Universidade Federal de Santa Maria (UFSM). Pesquisadora nas áreas de feminismo, direitos humanos e cultura política.
} 
Essa conquista impulsionou as mulheres do Movimento Olga Benário do Rio Grande do Sul a ocupar um prédio inabitado na Cidade de Porto Alegre, tanto para demandar políticas públicas de enfrentamento à violência, quanto fornecer às mulheres um espaço seguro de abrigamento e assistência jurídica, psicológica e social (CANOFRE, 2017). Atualmente, o espaço, conhecido como Casa de Referência da Mulher - Mulheres Mirabal, apresenta-se como um dos únicos locais para abrigamento de mulheres em situação de violência na capital gaúcha. Da mesma forma, as militantes do Olga Benário paulista ocuparam um edifício na cidade de Mauá, na região da grande ABC Paulista, instalando no mesmo o Centro de Referência da Mulher Helenira Preta, onde realizam-se atividades desde formação política até o abrigamento de mulheres vítimas de violência (LOPES, 2017; REDAÇÃO RBA, 2018).

A priori, o objetivo da primeira ocupação era pressionar o Estado a criar centros de referência para mulheres em situação de violência e, nos dois últimos casos, somar-se às poucas alternativas de abrigamento para essas mulheres, suprindo, assim, uma demanda social insatisfeita pelo Estado. Este objetivo, portanto, não parece estar ligado ao ato da ocupação dos imóveis em si, ou seja, à contestação da legalidade da propriedade privada e à desobediência dos mandados judiciais de despejo. Considerando esse cenário, este estudo propõe analisar a atuação do Movimento de Mulheres Olga Benário nas três Ocupações, através do escopo das teorias sobre movimentos feministas e desobediência civil. Serão acionadas as reflexões de John Rawls (1991) sobre desobediência civil, caracterizada enquanto um ato político, realizado na esfera pública, almejando modificar determinada lei ou política. Ademais, serão elencadas contribuições de teóricas feministas, a fim de identificar qual(is) perspectiva(s) são mobilizadas pelas participantes e quais suas principais demandas.

Pretende-se conhecer as motivações subjacentes à atuação do Movimento Olga Benário, tanto em termos da desobediência à lei em prol da resolução de necessidades imediatas, quanto do papel das Ocupações na busca por objetivos mais abrangentes. Para tal, serão analisados o funcionamento, a estrutura e a organização das Casas, e os objetivos que o movimento vislumbra em relação às Ocupações em seu diálogo com o Estado; paralelamente, busca-se compreender qual a interlocução entre as Ocupações e os movimentos feministas. Por fim, visa-se entender se as militantes consideram suas atividades de ocupação como um ato de desobediência civil e, se for o caso, como o justificam. Para tal, serão entrevistadas lideranças do Movimento Olga Benário e coordenadoras das Ocupações Tina Martins, Mirabal e Helenira Preta. Ademais, serão analisadas as páginas do Facebook e sites da Organização e das Casas.

O artigo está dividido em quatro partes, além desta introdução e das considerações finais. Primeiramente, será feita a discussão sobre desobediência civil e seus elementos constitutivos, conforme a teoria de John Rawls (1971; 1991); em um segundo momento, será apresentado um breve panorama sobre a trajetória e as demandas dos diferentes movimentos feministas. Posteriormente, apresenta-se o Movimento Olga Benário e as três Ocupações, junto de seus objetivos enquanto movimento social e feminista em relação às Casas de Referência e para além destas. Finalmente, será apresentado o feminismo que norteia as ações do Movimento Olga Benário, suas principais características e demandas, conforme coletado nas entrevistas.

\section{DESOBEDIÊNCIA CIVIL}

Sumariamente, a desobediência civil pode ser caracterizada como o ato de desobedecer uma lei considerada injusta por determinado grupo, motivado por uma boa ou justa causa. São exemplos 
típicos o ato de não pagar impostos para manifestar discordância com as práticas dos governantes, como realizado por Thouerau em meados de 1800, e os boicotes e greves executados por militantes do movimento anti apartheid na África do Sul e nos Estados Unidos, entre os quais, Nelson Mandela e Martin Luther King (BEDAU, 1991).

Os estudos voltados à análise e teorização da desobediência civil e obrigação política ganharam força a partir da década de 1960, com produções de filósofos e cientistas políticos, especialmente europeus e norte-americanos. Entre elas, destacam-se os escritos de Hannah Arendt, Crises da República (1973), da Revolução (1988) e Sobre a Violência (2009).

Conforme Arendt, a desobediência civil é pautada, por um lado, pela crise de legitimidade das autoridades e, por outro, pela demanda crescente por maior autonomia a atuação política dos governados como condição fundamental para exercer sua cidadania. Este pressuposto se baseia na noção de que o Direito deveria ser permeado por valores ligados aos processos históricos de formação de determinada comunidade. No entanto, devido a rapidez com que ocorrem mudanças sociais e culturais, os aparatos legais se deparam com dificuldades para adequar-se ao seu contexto, criando focos de insatisfação no seio da comunidade. "Não raro, inúmeras expectativas que, examinadas sob a ótica dos princípios fundamentais adotados, são legítimas, não encontram o devido amparo na legislação vigente" (BARK, SANTOS, 2012, p. 11). A consequência disso seria, portanto, a atuação dos governados com vistas a alcançar as mudanças desejadas.

Para Arendt (1973), a desobediência civil ocorre em duas situações: quando a sociedade percebe que o processo político tradicional não trará as conquistas almejadas, e; quando os cidadãos se defrontam com ações governamentais por eles consideradas ilegítimas e/ou inconstitucionais. Para ser fundamentada, a desobediência civil demanda coesão discursiva dos agentes em relação às ações a serem desenvolvidas. Em outras palavras, a desobediência é uma manifestação de poder não-violenta, amparada em um discurso que ratifica o potencial transformador das ações dos envolvidos, em busca de um objetivo comum.

A ausência da violência se dá, conforme Arendt (2009), em um contexto de contraposição à noção de poder. Para a autora, esses dois elementos são mutuamente excludentes. A violência é decorrente da arbitrariedade dos sujeitos e surge quando não há a possibilidade de ação conjunta; vez que a desobediência civil configura-se enquanto uma ação coletiva, ela se contrapõe à violência através do consenso fundado nas relações empreendidas pelos agentes. Nesse sentido, a autora nega que o poder seja detido pelo Estado e entende que o mesmo "passa a existir entre os homens quando eles agem juntos e desaparece quando eles se dispersam” (1983, p. 212-213).

A ênfase na ação coletiva em detrimento da individual é central na teoria arendtiana, pois faz com que o Estado se confronte com a necessidade de apoio efetivo dos cidadãos perante às suas ações, vez que este não detém o poder de antemão. A figura da desobediência civil surge, portanto, como uma forma de reinstaurar o espaço público, renovando e fortalecendo a comunidade e suas relações, assumindo, assim, caráter político (AGUIAR, 2011). A desobediência deve ser motivada por objetivos e valores comuns entre os agentes e deve ser praticada na esfera pública, a fim de dar visibilidade às suas reivindicações. Por fim, como mencionado, essas atitudes devem ser de natureza pacífica para assimilarem-se à noção de poder e força e não de violência. Conforme a autora, atos de desobediência civil, quando bem organizados, podem alcançar mudanças positivas e efetivas na legislação vigente, que podem estar desacreditadas em determinadas comunidades (ARENDT, 1983).

Uma vez que a desobediência civil se diferencia da desobediência comum às leis, como aquelas praticadas na violência urbana, por exemplo, ela deve ser tratada de forma distinta pelos governantes; 
seus agentes, não sendo infratores comuns, não poderiam ser julgados como tal, utilizando-se neste julgamento de argumentos baseados em questões morais maniqueístas, como estar agindo dentro ou fora da lei. Conforme Arendt (1999), os atos de desobediência civil podem ser compatíveis com as leis, visto que, enquanto os atos criminosos são praticados às escondidas e em benefício próprio, a desobediência civil é realizada coletiva e publicamente, em favor de um grupo ou causa específica. Nessa direção, "considerar as minorias desobedientes como rebeldes e traidores é ir contra a letra e o espírito de uma constituição, cujos criadores se mostraram especialmente sensíveis aos perigos do irrefreado domínio da maioria" (p. 84). Ademais, a não-violência é a característica que mais distancia os atos criminosos daqueles de desobediência civil.

A partir dessas reflexões, direcionamos nossa atenção à trajetória dos movimentos feministas, suas principais pautas e diferentes vertentes, com o intuito de, posteriormente, identificá-las com o Movimento Olga Benário e suas atividades de Ocupação.

\section{MOVIMENTOS FEMINISTAS}

Movimentos de mulheres e feministas são marcados por diferentes contextos históricos, os quais definem o tom das reivindicações e pautas de determinada época. Durante os debates iluministas do século XVIII, a igualdade formal orientou o princípio das manifestações feministas, momento de preocupação com a institucionalização e a extensão da cidadania feminina. Demandas como o direito ao voto feminino, principal bandeira da luta Sufragista, e o direito de acesso ao mercado de trabalho e à educação formal são as pautas que norteiam este momento embrionário do movimento feminista.

Tais feminismos foram protagonizados por mulheres brancas das elites europeias e norte-americana que excluíram de suas reivindicações e lutas as mulheres negras, das classes baixas e de países em desenvolvimento. Estas, por sua vez, organizaram movimentos próprios em busca de visibilização e efetivação de seus direitos, desafiando o sujeito "mulher" determinado pelo feminismo liberal. Exemplo disso é a manifestação de Sojourner Truth, mulher negra e ex-escrava que se tornou oradora, autora do discurso "E eu não sou uma mulher?", apresentado na Convenção dos Direitos das Mulheres em Ohio, em 1851 (RIBEIRO, 2016). Na ocasião, Sojourner anunciava as situações radicalmente distintas nas quais se encontravam as mulheres brancas e negras, apontando que, enquanto as brancas lutavam pelo direito ao voto, as mulheres negras lutavam para serem consideradas pessoas (TRUTH, 1851).

Em virtude dessas diferenças, a reivindicação por igualdade defendida pelo feminismo liberal passou a ser entendida como o anseio pela inclusão das mulheres em uma universalidade parcial. A própria ideia de cidadania abarcava minorias sob o conceito genérico de "indivíduo" na concepção liberal, privilegiando a posição masculina e branca sem, dessa forma, considerar os marcadores de gênero, raça e classe presentes na sociedade (PIOVESAN, 2012). Nesse momento, ganham força diferentes vertentes feministas, as quais são sintetizadas por Piovesan:

Reivindicações feministas, como o direito à igualdade formal (como pretendia o movimento feminista liberal), a liberdade sexual e reprodutiva (como pleiteava o movimento feminista libertário radical), o fomento da igualdade econômica (bandeira do movimento feminista socialista), a redefinição de papéis sociais 
(lema do movimento feminista existencialista) e o direito à diversidade sob as perspectivas de raça, etnia, dentre outras (como pretende o movimento feminista crítico e multicultural) (PIOVESAN, 2012, p.70).

Para fins deste estudo, dá-se ênfase à vertente socialista. Segundo esta corrente, o sujeito político da transformação é a classe trabalhadora que, conforme a perspectiva leninista, quando organizada, pode orientar a luta por transformação social, através de movimentos de massa que atuam como "correia de transmissão dos partidos" (SILVA, 2016, p. 174). Aqui, a libertação da mulher é encarada de forma simplória, como parte do processo geral de humanização de todo o gênero humano (SAFFIOTI, 1969). Dito de outra forma, o progresso de um sistema capitalista a um socialista seria condição suficiente para proporcionar às mulheres a igualdade perante os demais membros da sociedade. Para as feministas marxistas, no entanto,

[...] os homens da classe dominada funcionam, pois, como mediadores no processo de marginalização das mulheres de sua mesma classe da estrutura ocupacional, facilitando a realização dos interesses daqueles que na estrutura de classes ocupam uma posição oposta à sua (SAFFIOTI, 1969, p. 78).

As feministas marxistas filiam-se ao argumento de que não é possível atingir a igualdade entre os gêneros no sistema capitalista, pois este "se alimenta da preservação tanto da organização arcaica de uma atividade, como é o caso do emprego doméstico, como da apropriação redefinida de atributos femininos na indústria" (GONÇALVES, 2011, p. 128). No entanto, a mera emancipação econômica da mulher não é suficiente para libertá-la da discriminação social, vez que tal condição extrapola o sistema econômico e político, e assenta-se em sólidas bases culturais. Para Heleieth Saffioti (1969, p. 84), "certos padrões culturais forjados em outras estruturas persistem na nova, num descompasso de mudanças que desafia a validade de algumas teorias". Nesse diapasão, as análises feministas marxistas incorporam o elemento cultural, acionando os marcadores de gênero e raça em suas análises.

Apesar dos avanços trazidos pela corrente marxista, feministas negras passam a denunciar as produções desta e de outras vertentes por não analisarem, simultaneamente, as desigualdades de raça e de gênero, sem compreenderem como o racismo é elemento constitutivo das relações desiguais entre homens e mulheres e vice-versa. Com base nessas análises, surge a perspectiva feminista interseccional que, para Luiza Bairros:

seria fruto da necessidade de dar expressão a diferentes formas da experiência de ser negro (vivida através do gênero) e de ser mulher (vivida através da raça), o que torna supérfluas as discussões a respeito de qual seria a prioridade do movimento de mulheres negras - luta contra o sexismo ou contra o racismo? - já que as duas dimensões não podem ser separadas, Do ponto de vista da reflexão e da ação políticas, uma não existe sem a outra (BAIRROS, 1995, p. 461).

Como o conceito sugere, a vertente feminista interseccional dá ênfase à intersecção dos diferentes preconceitos e visibiliza as mulheres negras que, anteriormente, não tinham suas demandas contempladas nem pelo movimento feminista - branco e elitista -, nem pelo movimento 
negro - focado nas pautas de homens negros. Nesse sentido, auxilia na organização e na análise das pautas de mulheres negras e pobres, pois considera a tripla opressão a qual elas estão submetidas: racismo, sexismo e classismo (BAIRROS, 1995).

Sem a pretensão de esgotar a discussão acerca das vertentes feministas, entre as quais restam várias outras, como a perspectiva pós-colonial, decolonial, feminismocomunitário, etc., parte-se para a descrição da história do Movimento Olga Benário, das Ocupações, suas características e objetivos.

\section{MOVIMENTO OLGA BENÁRIO E AS OCUPAÇÕES}

O Movimento Olga Benário se originou na ocasião do Encontro de Mulheres Latino-Americanas e Caribenhas, ocorrido em 2011, na Venezuela. Conforme as militantes, seu surgimento se deve à necessidade da criação de um movimento específico para pautar questões das mulheres na luta por um Estado socialista. Soma-se a outros três movimentos - União dos Jovens Revolucionários, (UJR) Movimento Luta de Classes (MLC) e Movimento de Luta nos Bairros, Vilas e Favelas (MLB). Juntos, fazem parte da Unidade Popular pelo Socialismo (UP) ${ }^{2}$, partido político que pretende já participar do pleito eleitoral de $2020^{3}$. Conforme Thaís Vieira (2018a), coordenadora estadual do movimento em Minas Gerais, o Olga Benário está presente em mais de 20 estados do Brasil e se conecta a outras organizações latino-americanas, como as suas correspondentes na Argentina, no Uruguai, na Colômbia e na Costa Rica. Além disso, o Movimento se articula internacionalmente através da organização de Encontros Internacionais de Mulheres Latino-Americanas e Caribenhas (CARVALHO, 2019).

O Movimento conta com Coordenadorias a nível nacional, estadual e, em alguns casos, municipal, além de Núcleos de luta, presentes em universidades, escolas e bairros. Conforme Priscila Voigt (2018), coordenadora estadual no Rio Grande do Sul, as coordenadorias e os núcleos são responsáveis pelas atividades de luta que podem ir desde a alfabetização, até a formação política das mulheres, sempre enfatizando a busca pela sua emancipação. Entre suas atividades mais conhecidas, destacam-se as ocupações. Estas consistem no ato de utilizar-se de residências inabitadas e dar a elas uma função social que, conforme o artigo 182 da Constituição Federal Brasileira (1988), é obrigação de toda propriedade:

Art. 182. A política de desenvolvimento urbano, executada pelo Poder Público municipal, conforme diretrizes gerais fixadas em lei, tem por objetivo ordenar o pleno desenvolvimento das funções sociais da cidade e garantir o bem- estar de seus habitantes. (Regulamento) (Vide Lei n ${ }^{\circ}$ 13.311, de 11 de julho de 2016).

$\int 1^{\circ} \mathrm{O}$ plano diretor, aprovado pela Câmara Municipal, obrigatório para cidades com mais de vinte mil habitantes, é o instrumento básico da política de desenvolvimento e de expansão urbana.

2 A UP ainda não tem registro formalizado no Tribunal Superior Eleitoral, onde se exige quase 500 mil assinaturas para que o partido esteja apto a participar de pleitos eleitorais. Até o momento, a UP alcançou mais de 400 mil assinaturas.

3 Em virtude de os movimentos formarem parte de um partido político, não há uma militância em outros partidos, embora haja parcerias. Em 2018, por exemplo, as militantes do Olga Benário declararam apoio a duas candidatas do PSOL: Fernanda Melchionna (eleita à deputada federal pelo Rio Grande do Sul) e Luciana Genro (eleita à deputada estadual para a Assembleia Legislativa gaúcha). 
$\int 2^{\circ} \mathrm{A}$ propriedade urbana cumpre sua função social quando atende às exigências fundamentais de ordenação da cidade expressas no plano diretor.

$\int 3^{\circ}$ As desapropriações de imóveis urbanos serão feitas com prévia e justa indenização em dinheiro.

$\int 4^{\circ}$ É facultado ao Poder Público municipal, mediante lei específica para área incluída no plano diretor, exigir, nos termos da lei federal, do proprietário do solo urbano não edificado, subutilizado ou não utilizado, que promova seu adequado aproveitamento [...] (BRASIL, 1988).

Para Oliveira e Carvalho (2003, p. 64), tal função social provém de uma ética urbana "voltada à valorização do ambiente, cultura, cidadania e direitos humanos", para promover o plexo exercício do direito à cidade, a defesa dos direitos humanos, a redução das desigualdades e o aumento na qualidade de vida dos cidadãos. Com isso em mente, as militantes do Movimento argumentam que o artigo 182 fornece abertura constitucional à ocupação de todas as residências escolhidas, vez que estas estavam inabitadas e, em dois casos, abandonadas. Conforme Vieira (2018a), a ocupação ocorre só em locais onde não há uma função social. "Hoje, no Brasil, a gente tem mais casas vazias do que pessoas precisando de moradias. Então o que a gente busca é que essas moradias cumpram uma função social”.

Conforme Rafaela Carvalho (2019), coordenadora estadual do Movimento Olga Benário em São Paulo, as militantes não têm a intenção de contestar a legalidade da propriedade: "o nosso objetivo é atender as mulheres. Se não der para ser no local que a gente está hoje, que a prefeitura destine outro imóvel, pra gente não tem problema nenhum. A gente só precisa um espaço adequado para atender as mulheres em situação de violência". Segundo Voigt (2018), as militantes não solicitam recursos, nem profissionais: "a nossa briga não é pelo local, é pra ter um espaço para construir o projeto".

O que acontece é que, a partir do momento que a gente 'tá' ali dentro e tem todo um aparato militar para poder tirar a gente dali, a gente tem que resistir para poder ganhar as projeções da sociedade. Para que a sociedade nos reconheça não só como ocupantes de prédio. Porque tem uma diferença: quem invade um prédio, invade um prédio que 'tá' cumprindo uma função social, de moradia ou de emprego, de empresas e tal. Pra a gente ocupar um espaço, é porque ele não está cumprindo uma função social. Propriedades que estão [...] juntando mosquito da dengue, etc (VIEIRA, 2018a).

Carvalho (2019) aponta que a permanência e a resistência do movimento nas ocupações são uma necessidade: "as mulheres estão morrendo e não tem política pública pra isso. Inclusive, em Belo Horizonte e no Rio Grande do Sul, os próprios equipamentos públicos enviam mulheres para as nossas casas". Nesse sentido, defende que as ações do Movimento também se convertem em uma insistência para que o governo haja em favor das mulheres.

A primeira ocupação do Movimento ocorreu em Minas Gerais. De acordo com Vieira (2018a), em virtude da violência crescente contra as mulheres no estado, as militantes do Olga Benário sentiram a necessidade de realizar atos que fossem além das conhecidas Marchas realizadas no Dia 
Internacional da Mulher ${ }^{4}$. Isto pois, para as militantes, apesar dos movimentos que têm como palco as ruas serem importantes a nível de conscientização, estes, por si só, não são capazes de impactar suficientemente a vida das mulheres. Por essa razão, em 2016, no Dia Internacional da Mulher (8 de março), as militantes ocuparam o prédio do "bandejão" da Faculdade de Engenharia, da Universidade Federal de Minas Gerais, com o intuito de pressionar o Estado a criar mecanismos de enfrentamento à violência e de proteção às mulheres. A ocupação que, em princípio, duraria apenas um dia, se estendeu por três meses, pois, após chegar ao conhecimento dos(as) moradores(as) de Belo Horizonte, tornou-se um local procurado por mulheres que precisavam de atendimento e acolhimento. Conforme Vieira (2018a), o fim último da ocupação não era criar um Centro de Referência, mas exigir ações estatais nessa direção.

\footnotetext{
O objetivo "Casa de Referência" foi depois [...] quando a gente viu que a população realmente precisava da gente e que se a gente saísse dali o governo não ia fazer nada. E aí a gente teve que resistir. Mas o objetivo era que o estado criasse mais Casas-Abrigo para mulheres, num padrão onde as mulheres não fossem revitimizadas [...]. Só que a partir do momento que a gente ocupou e que a população descobriu, a gente começou a receber muitas mulheres vítimas de violência. Muitas mulheres que largaram suas casas [...] e foram pra lá pra tentar ter outra oportunidade na vida, porque elas ouviram falar que as meninas que 'tavam' ocupando o bandejão da UFMG iam "salvar a vida delas”. E aí a gente resolveu não desocupar (VIEIRA, 2018a).
}

Nesse momento, as militantes passaram a pensar a construção de uma Casa de Referência que fornecesse formação política, assistência social, jurídica e psicológica, empoderamento e, por fim, o abrigamento para mulheres em situação de violência. Após 89 dias de ocupação e de negociação com os governantes, as ativistas encontraram uma propriedade estadual desocupada, a qual foi cedida por dois anos pelo Governo de Minas Gerais. Em 3 de junho de 2016, a Ocupação mudou-se para a residência e efetivou-se como a Casa de Referência de Mulheres Tina Martins. Atualmente, a Casa conta com várias coordenadoras voluntárias que se alternam na sua manutenção, e fornece serviços gratuitos de psicólogas, advogadas e assistentes sociais. São oferecidas 12 vagas para mulheres e 4 para crianças, todas rotativas; nelas, as mulheres não possuem um prazo determinado de permanecimento. E "quando elas saem da Casa, elas continuam podendo ser dependentes da assistência jurídica, psicológica e social, sem custo nenhum” (VIEIRA, 2018a).

Inspiradas na construção da Casa Tina Martins, as militantes do Movimento Olga Benário do Rio Grande do Sul ocuparam, no Dia Internacional da Não-Violência contra a Mulher de 2016 (25 de novembro), um casarão pertencente aos Irmãos Salesianos, em Porto Alegre. A propriedade, que estava inabitada há mais de quatro anos, tornou-se um dos únicos Centros de Referência para Mulheres em situação de violência da capital gaúcha, que conta com apenas uma Casa-Abrigo com 14 vagas (GOMES, 2018; CANOFRE, 2018).

Desde os seis meses de ocupação, a casa passou a sofrer ameaças de reintegração de posse, com o argumento de implantar no local um projeto para adolescentes em situação de vulnerabilidade social. Resistindo à ordem judicial, as militantes receberam um novo mandado de despejo e a promessa do governo em destinar a elas um novo prédio (MULLER, 2017). Após ocuparem o

4 Movimentos como o 8M, que incentivam a paralização do trabalho feminino durante o Dia Internacional da Mulher, se destacam entre as marchas mais conhecidas e aderidas mundialmente. 
mesmo, as militantes receberam nova ameaça de reintegração, suspendida uma semana depois. No dia 27 de setembro de 2018, o movimento entregou as chaves da primeira Casa, com a expectativa de que o novo imóvel fosse legalizado pelo Município. Até o momento, a Casa permanece em processo judicial, pois não foi oficialmente fornecida pelo poder público.

A Casa Mulheres Mirabal se impõe, assim, como uma estratégia para comprometer o poder público a encontrar uma alternativa para as mulheres em situação de violência. Nela as militantes buscam oferecer uma referência às mulheres do bairro no qual a casa está instalada, onde elas possam se informar, estudar e receber apoio. Atualmente, são abrigadas 9 mulheres e 4 crianças e estima-se que outras 300 tenham recebido atendimento desde o início da ocupação, que incluem: assistência jurídica e psicológica e acolhimento temporário - todos serviços gratuitos. Assim como na Tina Martins, as mulheres não têm prazo para sair da casa; cada uma leva um tempo específico, conforme se recuperam das agressões sofridas e encontram um lugar para morar e trabalhar. Mesmo depois de saírem do acolhimento, as militantes buscam monitorá-las para, de acordo com Vieira (2018a), "garantir que elas já estejam aptas para a sua reinserção na sociedade".

A terceira Ocupação realizada pelo Movimento Olga Benário ocorreu em 2017, na cidade de Mauá, na região do grande $\mathrm{ABC}$ paulista, no Dia Internacional da Mulher Negra, Latina e Caribenha (25 julho). Primeiramente, as militantes ocuparam um prédio no centro da cidade onde estiveram por uma semana. Em função das condições insalubres nas quais se encontrava o imóvel que impediriam o atendimento às mulheres, as militantes liberaram o mesmo, mediante a assinatura de uma carta-compromisso pela prefeitura da cidade, onde se firmaram atribuições destinadas a criar uma Casa-Abrigo. Após o descumprimento consecutivo das promessas do governo e outros entraves políticos, como a prisão do prefeito da cidade ${ }^{5}$, as ativistas voltam a ocupar um prédio municipal, em 28 de setembro de 2018, edifício que estava inabitado desde 2016. Conforme Carvalho (2019), a ocupação se deu em função da ausência de Casas para mulheres em situação de violência na cidade de Mauá: "as mulheres não tinham mesmo condição de sair de qualquer situação de violência".

O movimento de mulheres Olga Benário realizou a ocupação de uma casa abandonada para a construção de uma Casa de Referências para mulheres na cidade de Mauá. A vida das mulheres no sistema em que vivemos está cada vez pior, com índices de violência e estupro que só aumentam, principalmente das mulheres negras. Por esse motivo e para defender a vida das mulheres foi organizada a ocupação [...] (MOVIMENTO DE MULHERES OLGA BENÁRIO, 2018). ${ }^{6}$

O objetivo imediato da Ocupação Helerina é ajudar as mulheres em situação de violência. No entanto, também entende a necessidade de pressionar o Estado a tomar parte na responsabilização de proteção a essas mulheres: "O nosso movimento, sozinho, não tem condições de suprir essa necessidade que é um dever do Estado" (CARVALHO, 2019). Portanto, desde a segunda ocupação, a Casa Helerina Preta se estabelece como um dos únicos abrigos para mulheres em

5 O ex-prefeito de Mauá, Átila Jacomussi (PSB), foi preso pela Polícia Federal em 13 de dezembro de 2018, acusado de chefiar esquema de corrupção conhecido como "mensalinho" (CERÂNTULA; TAVARES, 2018).

6 Disponível em: <https://www.facebook.com/casahelenirapreta/>. Acesso em: 04 dez. 2018. 
situação de violência do $\mathrm{ABC}$ paulista ${ }^{7}$ e fornece, assim com as outras duas Casas, assistência jurídica, psicológica e social. As militantes organizam feiras e atividades para as abrigadas e para o público externo, visando arrecadar verbas para a manutenção da Casa, vez que, por ora, não contam com nenhum tipo de financiamento público ou privado (CASA HELENIRA PRETA DE REFERÊNCIA DA MULHER, 2018).

Temos a certeza de que temos condições de realizar esse atendimento com apoio da população e de profissionais que, junto conosco, realizem esse atendimento. [...] Conclamamos a Prefeitura, o governo do Estado e todos os entes públicos da região do ABC a apoiarem a organização autônoma das mulheres em defesa de políticas públicas para as vítimas de violência (VIEIRA, 2018b).

De acordo com as coordenadoras, as militantes buscam construir uma direção horizontal em todas as casas, sem criar uma separação entre a coordenadora e a abrigada: "a gente dorme nas mesmas condições, a gente come a mesma comida, sentada na mesma mesa, no mesmo horário das mulheres [abrigadas]. A gente tem um convívio social muito grande com elas" (VIEIRA, 2018a). Além disso, todos os móveis são frutos de doação da população ${ }^{8}$ e das próprias militantes; as Casas são autossustentáveis, mas há barganha com o estado quanto à água e à energia.

\section{OBJETIVOS DO MOVIMENTO}

Conforme Thaís Vieira (2018a), "é necessário que o fim último de todo movimento social seja um partido institucionalizado para negociar e barganhar”. Para as coordenadoras, é essencial fazer parte do jogo institucional, embora buscando combater o sistema capitalista e construir uma forma de sociedade baseada em valores socialistas. "Nós não temos ilusão nenhuma de que a política que está aí hoje vai resolver nossos problemas. Mas se a gente tiver alguma representação que faça o mínimo por nós, isso já é muito importante" (CARVALHO, 2019). Por essa razão, as coordenadoras reiteram a necessidade de o movimento social manter-se nas ruas. Referindo-se à UP, Carvalho (2019) aponta que o movimento "não descarta a possibilidade de uma representação política institucional [...], mas não é isso que vai resolver”. Para elas é primordial, portanto

Cuidar bastante para que o movimento social continue na sua luta. O parlamento tem que servir para que os movimentos sociais cresçam, e não o contrário; colocando todos os movimentos nos gabinetes e acabando com a luta. Ali deve ser mais um espaço para fortalecer a luta e não para nos salvar. É nessa perspectiva que a gente 'tá' formando o partido (VOIGT, 2018).

7 Em todo o ABC paulista, há apenas uma Delegacia de Atendimento Especializado à Mulher e três Casas Abrigo, com 40 vagas cada.

8 Apesar do apoio de parte da população, as coordenadoras relatam várias ameaças também sofridas pelas militantes. 
Conforme o site do Olga Benário9, incluem-se nos objetivos do movimento: o combate à espoliação e às guerras imperialistas; a luta pela garantia de emprego e igualdade salarial para trabalho de igual valor; combate à exploração de mulheres e crianças; enfrentamento a todas as formas de discriminação contra as mulheres; amplo acesso à saúde, planejamento familiar e direitos reprodutivos; construção de creches, restaurantes e lavanderias públicas; combate à violência doméstica e sexual; luta pela garantia de acesso à moradia digna e educação; igualdade de direitos, e; a evolução para o socialismo.

Para além de objetivos pontuais, as militantes projetam maior aproximação com as mulheres da periferia e com as operárias, e a manutenção do trabalho feito nas universidades. Para elas, a função de um movimento social é preservar o trabalho de base nas ruas. O Movimento se alia, portanto, às mulheres pobres com maior dificuldade de acesso aos equipamentos públicos: "é com vista a essas mulheres que a gente atua. Por mais que todas as mulheres, pelo simples fato de serem mulheres, sofrem pelo machismo, essas sofrem de uma maneira muito mais cruel" (CARVALHO, 2019).

Nesse sentido, os objetivos do movimento vão além da Ocupação de prédios e da construção de abrigamentos para mulheres em situação de violência, pois, mesmo que o Estado viesse a sanar as necessidades referentes às Casas de acolhimento, várias outras bandeiras do movimento se manteriam. "As lutas vão mudando, elas vão se moldando de outras formas [...] de acordo com as necessidades da mulher que vão surgindo" (VIEIRA, 2018a). Ademais, a ação conjunta com a UJR, a MLC e a MLB permite o trânsito entre as pautas e edifica a convergência de seus valores, no objetivo máximo de progredir a um sistema socialista que, entre outras coisas, democratize o espaço urbano e reduza as desigualdades.

As ativistas almejam, portanto, o seu fortalecimento enquanto movimento, embora diante de possíveis perseguições políticas, promessas de criminalização dos movimentos sociais e de tifipicação de ocupações enquanto atos terroristas, conforme especulações acerca do governo que assumiu a Presidência da República em janeiro de $2019^{10}$. A maior ameaça nesses termos, até o momento, é o Relatório ${ }^{11}$ que sugere adições à Lei 13.260/2016, responsável por prever, entre os atos terroristas, qualquer tentativa de sabotar o funcionamento ou obter o controle total ou parcial de escolas ou locais onde funcionem serviços públicos essenciais. A sugestão do Relatório é no sentido de ampliar o conceito de terrorismo e incluir neste atos que visem "coagir autoridade, concessionário ou permissionário do poder público a adotar determinada conduta" (BRASIL, 2016).

De acordo com Voigt (2018), o autoritarismo, as ameaças e o terror são postas de modo a pressionar para que a comunidade não se organize. A coordenadora acredita que, em função de políticas dessa natureza, os próximos anos serão um momento de mais enfrentamento, onde realizar ações de vanguarda se tornam bastante perigosas. Por essa razão, compreende a necessidade de ações de massa. No mesmo diapasão, Carvalho (2019) considera que os novos governos acirrarão a luta de classes, o que torna mais difícil a condição do Movimento para atuar no âmbito

9 Disponível em: <http://movimentodemulheresolgabenario.blogspot.com/p/quem-somos.html>. Acesso em: 12 nov. 2018.

10 Jair Bolsonaro, eleito presidente em 2018, é publicamente contrário e já se pronunciou de forma bastante agressiva quanto à atuação de partidos de esquerda e a ações de ocupações como as do Movimento de Trabalhadores sem Teto (MTST).

11 Redigido pelo ex-senador Magno Malta, um dos apoiadores de Bolsonaro. 
público. Neste novo governo, as coordenadoras não visualizam uma conjuntura favorável às suas ações: "num governo extremamente liberal e com um partido que não acredita nas discriminações afirmativas, a chance de a gente ser retirada [das Casas] 'na bala', é muito grande" (VIEIRA, 2018a). No entanto, a coordenadora reitera que o Movimento não vai deixar de existir com a entrada de um governo autoritário: "O que a gente vai fazer é resistir contra esse governo" (idem). Carvalho (2019) reitera o compromisso do Movimento em continuar atuando e garante que, apesar das dificuldades, as militantes permanecerão nas suas lutas.

\subsection{FEMINISMO DO OLGA BENÁRIO}

Conforme Carvalho (2019), o Olga Benário "luta na prática pela emancipação das mulheres". Contudo, compreende que tal emancipação não tem espaço no sistema capitalista. Por essa razão, lutam também pelo socialismo: "quando não tiver mais opressão de classe, aí vai ser possível uma condição em que não haja mais a opressão de gênero" (idem). Assim, o Movimento Olga Benário filia-se à vertente feminista socialista. A Unidade Popular pelo Socialismo (UP) se orienta pela corrente do socialismo marxista-leninista e, a priori, todos os seus membros compartilham dos mesmos valores. O mesmo ocorre no Movimento Olga Benário. Para elas, a emancipação da mulher não é possível no capitalismo; da mesma forma, o progresso do sistema capitalista ao socialista não será viável sem a presença das mulheres. Nesse sentido, as militantes não reduzem a conquista de um sistema socialista à luta de classes; entendem que a ênfase nas relações de poder entre os gêneros e nas desigualdades raciais é essencial, vez que "tanto o machismo, quanto o racismo justificam maior exploração sobre as mulheres brancas e negras e sobre os negros” (VOIGT, 2018).

\footnotetext{
A gente almeja chegar no socialismo, na socialização dos meios de produção. Mas o debate cultural vai ter que ser aprofundado. Não significa que porque conseguimos a socialização dos meios de produção, acabou o machismo [...] Não, vai ter que ter muita educação, muita formação política, e as mulheres vão ter que fazer parte disso [...] Não vai ter emancipação das mulheres neste sistema. Sem elas, não tem como haver nem manter a revolução. São duas coisas interligadas (VOIGT, 2018).
}

As militantes compreendem a situação de inferioridade da mulher como originada na propriedade privada que relega a mesma ao ambiente doméstico. Nessa estrutura, todas as mulheres sofrem pela desigualdade, mas de diferentes formas, conforme os demais marcadores sociais aos quais pertencem. O mesmo ocorre com as diferentes violências sofridas pelas mulheres; são mais atingidas as negras e as de classe baixa. Por esta razão, o Movimento Olga Benário prioriza a luta das mulheres trabalhadoras, campesinas, domésticas e de periferia - aquelas que mais sofrem com o capitalismo. Conforme Vieira (2018a), o valor norteador do movimento é o de produzir igualdade entre homens e mulheres, mas também entre mulheres. Isto pois considera que o "sistema capitalista é muito opressor e não traz a igualdade entre as mulheres. E mulheres indígenas, negras, operárias não têm os mesmos direitos de mulheres brancas e de classe média, nem as mesmas oportunidades".

Além disso, o Movimento preza pela união entre as mulheres por considerar que podem alcançar mudanças efetivas quando trabalham conjuntamente. Ao mesmo tempo, entendem que a reação do poder público, como os mandados judiciais de desocupação das Casas e a negligência em cumprir as promessas feitas ao movimento, pode estar ligada a essa capacidade potencial para mudanças que as organizações de mulheres detêm. Conforme Voigt: 


\begin{abstract}
É óbvio que eles não querem que [a ocupação] vire um exemplo. O quanto que as mulheres organizadas podem construir. O poder de uma organização de mulheres, fortalecendo outras mulheres [...] Então óbvio que isso gera medo para a estrutura da sociedade. Porque eles nos veem como uma ameaça: "essas mulheres ocuparam um prédio, ocuparam outro... E estão aí se tornando exemplo para as outras mulheres". Então isso é um perigo. A gente pensa que essa intransigência tão grande do município também tem a ver com isso. Por causa do exemplo do que as mulheres são capazes de construir quando se organizam (VOIGT, 2018).
\end{abstract}

As orientações feministas do Movimento estão de acordo com as ideias propostas por feministas marxistas, as quais advogam pelo vínculo entre o sistema capitalista, racista e machista, onde mulheres negras e pobres são as mais afetadas pela discriminação e pela violência (SAFFIOTI, 1969). Da mesma forma, as militantes apresentam, de modo latente, a preocupação com a intersecção das desigualdades, como propõe o feminismo interseccional (BAIRROS, 1995), sempre reiterando a necessidade de o Movimento apoiar e manter-se próximo a mulheres em distintos eixos sociais e raciais.

Destaca-se, também, a escolha das datas de ocupação, bem como do nome das Casas. Esta reitera o compromisso das militantes com a visibilização de mulheres em distintos eixos sociais e raciais e as lutas das mesmas pelo fim da violência, do autoritarismo e da exploração. As datas simbolizam essas lutas: Dia Internacional da Mulher, Dia da Não-Violência contra a Mulher e Dia da Mulher Negra, Latina e Caribenha. As Casas, por sua vez, homenageiam Tina Martins, ativista gaúcha que lutou pelos direitos dos trabalhadores no início do século XX, das irmãs Mirabal, assassinadas pela ditadura de Trujillo na República Dominicana, e de Helenira Preta, mulher negra, assassinada pela ditadura brasileira.

\title{
6 CONSIDERAÇÕES FINAIS
}

Conforme as coordenadoras, o movimento se apoia no artigo 182 da Constituição Federal, que garante o uso social da propriedade. Nesse sentido, a ocupação não seria, em si, um ato de desobediência, vez que os prédios escolhidos estavam inabitados há anos e, portanto, não cumpriam nenhuma função social. A desobediência se inicia a partir do momento em que há uma decisão judicial de reintegração dos imóveis, a qual as militantes optam por resistir. Neste sentido, o objetivo imedtiado do Movimento Olga Benário não é contestar a propriedade privada, mas pressionar o Estado a criar mecanismos e políticas para o enfrentamento à violência e, em última instância, assumir parte desses mecanismos. E, embora não busquem contestar diretamente a legalidade da propriedade, são aliadas a outros movimentos, entre os quais o Movimento de Lutas nos Bairros, Vilas e Favelas (MLB) que têm, em seu cerne, tal contestação. Ademais, advogam por uma sociedade justa e igualitária, na qual há a socialização dos meios de produção e a democratização do espaço urbano. Significa dizer que, mesmo se o Estado viesse a prover todos os mecanismos necessários para a proteção de mulheres em situação de violência, o Movimento se manteria, pois outras demandas continuariam existindo, como o fim da desigualdade salarial, a legalização do aborto e, finalmente, a conquista de um sistema socialista.

As ocupações podem ser caracterizadas, portanto, enquanto um ato de desobediência civil, especialmente quando se considera a presença dos distintos elementos propostos por John Rawls (1971; 1991): uma ação política, realizada publicamente, que almeja a transformação de uma lei ou política considerada injusta por determinado grupo; é um ato não-violento; que se dá em uma 
sociedade "quase justa". Ademais, é uma atitude justificada, conforme a teoria ralwsaniana, vez que contém as condições para a sua legitimidade, em especial, a violação dos princípios da justiça - pois às mulheres não é provido o pleno exercício do direito a uma vida sem violência -, e o fato de a ocupação ser realizada em circunstâncias de esgotamento dos recursos políticos. Situação demonstrada na falta de políticas públicas para mulheres em situação de violência que levaram as militantes a ocupar as três Casas, e no descumprimento das promessas do governo da cidade de Mauá em relação à proteção das mulheres, condição que levou a reocupação do prédio pelas ativistas da Casa Helenira Preta. Além disso, a possível tipificação das ocupações enquanto atos terroristas demonstra a intenção do poder público em tratá-las enquanto criminosas e agir sem a criticidade demandada por Rawls, mesmo que as militantes estejam apresentando seus objetivos publicamente, amparadas constitucionalmente.

O elemento político das ocupações se mostra presente, especialmente quanto às orientações feministas que norteiam as ações do Movimento. As militantes demonstram filiação a uma perspectiva socialista da sociedade, onde busca-se produzir igualdade entre homens e mulheres e alcançar a igualdade entre as próprias mulheres, característica do feminismo marxista. Neste, enfatiza-se as diferentes opressões pelas quais passam mulheres de distintos lugares sociais, como as negras perante as brancas, as de classes baixas frente às de classes altas, etc. Ademais, as ativistas preocupam-se com a intersecção dessas diferentes opressões e entendem que mulheres negras e pobres devem receber prioridade nas ações do Movimento, em virtude de sua posição de vulnerabilidade social.

\section{REFERÊNCIAS}

AGUIAR, O. A. A dimensão ética da desobediência civil. Universidade Federal do Ceará (UFC), 2011.

ARENDT, Hannah. A condição humana. Tradução de Roberto Raposo. Rio de Janeiro: Forense, 1983.

. Crises da República. São Paulo: Perspectiva, 1973.

Da revolução. Tradução de Fernando Dídimo Vieira: São Paulo: Ática; Brasília: Ed. UnB, 1988.

Eichmann em Jerusalém: um relato sobre a banalidade do mal. Trad. José Rubens Siqueira. São Paulo: Companhia das Letras, 1999.

Sobre a violência. Tradução de André de Macedo Duarte: Rio de Janeiro: Civilização Brasileira, 2009.

BARK, Gehad. M.; SANTOS, André. F. P. R. Desobediência Civil como Ação Política em Hannah Arendt. Derecho y Cambio Social, v. IX, p.1 - 14, 2012.

BAIRROS, Luiza. Nossos feminismos revisitados. Estudos feministas, n. 2, 1995.

BEDAU, Hugo (eds.) Civil Disobedience in Focus. Londres: Routledge, 1991.

BRASIL. Constituição Federal de 1988. Brasília, DF, 1988. 
Lei $\mathbf{N}^{\circ} 13.260$ de 16 de março de 2016. Regulamenta o disposto no inciso XLIII do art. $5^{\circ}$ da Constituição Federal, disciplinando o terrorismo, tratando de disposições investigatórias e processuais e reformulando o conceito de organização terrorista; e altera as Leis $\mathrm{n}^{\text {os }} \mathbf{7 . 9 6 0}$, de 21 de dezembro de 1989, e 12.850, de 2 de agosto de 2013. Brasília, 2016.

CANOFRE, Fernanda. Ocupação Mirabal: Como funciona uma ocupação de mulheres para mulheres. Sul 21, Porto Alegre, 13 de janeiro de 2017. Disponível em: <https://www.sul21.com.br/areazero/2017/01/ocupacao-mirabal-como-funciona-uma-ocupacao-de-mulheres-para-mulheres/>. Acesso em: 30 de setembro de 2018.

CARVALHO, Rafaela. Entrevista realizada no dia 11 de janeiro de 2019. Porto Alegre, 2019.

CASA HELENIRA PRETA DE REFERÊNCIA DA MULHER. Página do Facebook. Disponível em: $<$ https:// www.facebook.com/pg/casahelenirapreta/posts/>. Acesso em: 11 dez. 2018

CERÂNTULA, Robinson; TAVARES, Bruno. PF prende prefeito de Mauá e faz buscas em gabinetes de 22 vereadores. São Paulo: G1, 13 dez. 2018. Disponível em: <https://g1.globo.com/sp/sao-paulo/noticia/2018/12/13/ pf-faz-operacao-para-cumprir-mandados-de-prisao-e-busca-na-prefeitura-e-camara-de-vereadores-de-maua.ghtml $>$. Acesso em: 12 jan. 2019.

GOMES, Luís Eduardo. Sem avanço em acordo, Ocupação Mirabal recebe nova ordem de despejo. Sul 21, Porto Alegre, 30 de agosto de 2018. Disponível em: <https://www.sul21.com.br/ultimas-noticias/geral/2018/08/ sem-avanco-em-acordo-ocupacao-mirabal-recebe-nova-ordem-de-despejo/>. Acesso em: 28 de setembro de 2018.

GONÇALVES, Renata. O feminismo marxista de Heleieth Saffioti. Lutas Sociais, São Paulo, n.27, p.119-131, 20 sem. 2011.

LOPES, Luiza. Mulheres cobram centro de apoio contra violência em Mauá. Mauá: Agência Mural, 2017. Disponível em: < https://mural.blogfolha.uol.com.br/2017/08/22/mulheres-cobram-centro-de-apoio-contra-violencia-em-maua/>. Acesso em: 07 dez. 2018.

MOVIMENTO DE MULHERES OLGA BENÁRIO. Quem somos? Disponível em: < http://movimentodemulheresolgabenario.blogspot.com/p/quem-somos.html>. Acesso em: 05 dez. 2018.

MULLER, Bárbara. Proprietária do prédio que abriga ocupação Mirabal quer implantar projeto para adolescentes no local. Zero Hora, Porto Alegre, 07 de julho de 2017. Disponível em: < https://gauchazh.clicrbs.com.br/ porto-alegre/noticia/2017/06/proprietaria-do-predio-que-abriga-ocupacao-mirabal-quer-implantar-projeto-para-adolescentes-no-local-9810513.html>. Acesso em: 27 de setembro de 2018.

OLIVEIRA, A . DE C.: CARVALHO P.C.P. Estatuto da Cidade: anotações à lei 10.257, de 10.07.2001, Curitiba: Juruá.

PIOVESAN, Flávia. A proteção internacional dos direitos humanos das mulheres. R. EMERJ,15, 57 (Edição Especial), p. 70-89, 2012.

PORTO, Tiago. Devemos obedecer a leis injustaṧ O Direito à Desobediência Civil em John Rawls. Peri, v. 07, n. 01, 2015.

REDE BRASIL ATUAL (RBA). Mulheres de Mauá ocupam imóvel por abertura de Casa de Referência. São Paulo, 2018. Disponível em: <https://www.redebrasilatual.com.br/cidadania/2018/10/mulheres-fazem-ocupacao-por-abertura-de-casa-de-referencia-em-maua>. Acesso em: 10 dez. 2018.

RIBEIRO, Djamila. O que é lugar de fala? Editora Letramento, 2016.

SAFFIOTI, Heleieth. A mulher na sociedade de classes: mito e realidade. São Paulo: Quatro Artes, 1969. 
SALLES, Eduardo Baldissera Carvalho; MATIELLO, Caticlys Niélys. Os fundamentos da desobediência civil em John Rawls. Revista de Teorias da Justiça, da Decisão e da Argumentação Jurídica, e-ISSN: 2525-9644, Brasília, v. 2, n. 1, p. 228 - 246 , jan/Jun. 2016.

SILVA, Carmen S. M. Feminismo popular e lutas antissistêmicas. Recife: Edições SOS Corpo, 2016.

SUAREZ, Joana. Ocupação se muda e vira Casa de Referência à vítima. O Tempo, 2016. Disponível em: $<$ https://www.otempo.com.br/cidades/ocupa \%C3\%A7\%C3\%A3o-se-muda-e-vira-casa-de-refer $\%$ C3\%AAncia-\%C3\%A0-v\%C3\%ADtima-1.1313675>. Acesso em: 09 dez. 2018.

TRAMONTINA, Robison; MOZITEC, Vinícius. A concepção de desobediência civil em John Rawls. Unoesc International Legal Seminar, Chapecó, v. 1, n. 1, 2012.

TRUTH, Sojouner. E eu não sou uma mulher? In: Convenção dos Direitos da Mulher, Ohio, 1851. Disponível em: < https://www.geledes.org.br/e-nao-sou-uma-mulher-sojourner-truth/>. Acesso em: 12 dez. 2018.

VARGAS, Bruna. “A gente vai resistir”, dizem coordenadoras da Ocupação Mirabal após determinação de reintegração de posse. Zero Hora, Porto Alegre, 12 de julho de 2018. Disponível em: < https://gauchazh.clicrbs. com.br/porto-alegre/noticia/2018/07/a-gente-vai-resistir-dizem-coordenadoras-da-ocupacao-mirabal-apos-determinacao-de-reintegracao-de-posse-cjij5xutf0rkd01qoyi7reb47.html>. Acesso em: 29 de setembro de 2018.

VIEIRA, Rayane. Casa Helenira Preta de referência da mulher é inaugurada por nova ocupação em Mauá. Mídia Ninja, 2018b. Disponível em: < http://midianinja.org/news/casa-helenira-preta-de-referencia-da-mulher-e-inaugurada-por-nova-ocupacao-em-maua/>. Acesso em: 10 dez. 2018b.

VIEIRA, Thaís. Entrevista realizada em 24 de outubro de 2018. Porto Alegre, 2018a.

VOIGT, Priscila. Entrevista realizada em 27 de outubro de 2018. Porto Alegre, 2018. 